\title{
Coloduodenal fistula due to signet-ring cells adenocarcinoma
}

\author{
João Santos-Antunes • Regina Gonçalves • Susana Lopes • \\ Guilherme Macedo
}

Accepted: 23 December 2014 /Published online: 16 January 2015

(C) Springer-Verlag Berlin Heidelberg 2015

\section{Dear Editor:}

A 32 years-old male was admitted due to rectal bleeding and diarrhea started 2 months before. He was pale, with fever and with signs of severe malnutrition. Blood count showed anemia (Hemoglobin $7.7 \mathrm{~g} / \mathrm{dL}$ ), hypoalbuminemia $(22 \mathrm{~g} / \mathrm{dL})$, and elevated C-Reactive Protein $(202 \mathrm{mg} / \mathrm{L})$. Colonoscopy showed an ulcerated stenosis with necrotic tissue proximally in the ascending colon that did not allow progression of the scope. In upper endoscopy, a necrotic cavity was seen in the duodenal bulb and, advancing the scope, we went directly to the colon. Biopsies on both exams were diagnostic of signetring cells adenocarcinoma. CT scan also revealed duodenocolic fistula. During surgery, this lesion was considered unresectable, and chemotherapy was not feasible due to his very poor health status. He died 2 months later.

Coloduodenal fistulas are rarely described, and this is the first report of a signet-ring cells adenocarcinoma in this setting. In the literature, we found a few reports from fistulas due to Crohn's Disease [1] (probably the most common etiology [2]), tuberculosis [3], gallstone disease [4], and malignancy from hepatic flexure [1]. These fistulas are normally detected by cross-sectional studies and the lumen of the fistula is usually narrow. By contrast, in our case, the fistula was very large and it was diagnosed by endoscopy.

Besides, nutritional support, treatment is primary surgical, if possible with an en bloc duodenopancreatectomy. Prognosis depends on the etiology and patient performance status.

\section{References}

1. Pichney LS, Fantry GT, Graham SM (1992) Gastro-colic and duodenocolic fistulas in Crohn's disease. J Clin Gastroenterol 15: 205-211

2. Kamath AS, Iqbal CW, Pham TH, Wolff BG, Chua HK, Donohue JH, Cima RR, Devine RM (2011) Management and outcomes of primary coloduodenal fistulas. J Gastrointest Surg 15(10):1706-1711

3. Tsukada T, Nishioka T, Ishida N, Matsumoto T, Mitani H, Kobayashi K, Sekine T, Nakazawa S, Kusagawa M, Aonuma H et al (1995) Colonic and peritoneal tuberculosis associated with coloduodenal fistula. J Gastroenterol 30(4):520-523

4. Pangan JC, Estrada R, Rosales R (1984) Cholecystoduodenocolic fistula with recurrent gallstone ileus. Arch Surg 119(10):1201-1203

J. Santos-Antunes $(\bowtie) \cdot R$. Gonçalves $\cdot$ S. Lopes $\cdot$ G. Macedo Gastroenterology Department, Faculty of Medicine, Hospital de São João, Alameda Prof. Hernani Monteiro, 4200-319 Porto, Portugal e-mail: joao.claudio.antunes@gmail.com 